\title{
Dye Decolourisation Using Two Klebsiella Strains
}

\author{
Ewa Zabłocka-Godlewska • Wioletta Przystaś • \\ Elżbieta Grabińska-Sota
}

Received: 9 June 2014 / Accepted: 25 November 2014 /Published online: 11 December 2014

(C) The Author(s) 2014. This article is published with open access at Springerlink.com

\begin{abstract}
This study aimed to decolourise different dyes using two Klebsiella strains (Bz4 and Rz7) in different concentrations and incubation conditions. Azo (Evans blue (EB)) and triphenylmethane (brilliant green (BG)) dyes were used individually and in mixture. The toxicity of the biotransformation products was estimated. Both strains had a significant potential to decolourise the dyes in the fluorone, azo and triphenylmethane classes. The type and concentration of dye affects the decolourisation effectiveness. Differences in the dye removal potential were observed particularly in the main experiment. The best results were obtained for Bz4 in the samples with EB (up to $95.4 \%$ ) and dye mixture (up to $99 \%$ ) and for Rz7 with BG (100\%). The living and dead biomass of the strain Bz4 highly absorbs the dyes. Significant effect of the process conditions was noticed for both strains. The best results were obtained in static and semistatic samples (89-99\%) for the removal of EB and a mixture of dyes and in static samples $(100 \%)$ for BG. The decrease in zootoxicity (from class $\mathrm{IV} / \mathrm{V}$ ) was noticed in all samples with living biomass of the strain Bz4 (to class III/IV) and in samples with single
\end{abstract}

\footnotetext{
E. Zabłocka-Godlewska ( $\bowtie) \cdot$ W. Przystaś •

E. Grabińska-Sota

Environmental Biotechnology Department, Silesian

University of Technology,

Akademicka 2A, 44-100 Gliwice, Poland

e-mail: ewa.zablocka-godlewska@polsl.pl

W. Przystaś

e-mail: wioletta.przystas@polsl.pl

E. Grabińska-Sota

e-mail: elzbieta.g.sota@polsl.pl
}

dyes for Rz7 (to class III/IV). The decrease in phytotoxicity (from class III/IV) was noticed for Bz4 in the samples with BG and a mixture (to class III) and for $\mathrm{Rz7}$ in the samples with BG (to class III). The process conditions did not affect the changes in toxicity after the process.

Keywords Klebsiella - Azo dyes · Triphenylmethane dyes - Dyes mixture - Decolourisation - Zootoxicity · Phytotoxicity

\section{Introduction}

Azo and triphenylmethane (TPM) dyes are classes of synthetic dyes that are used in many industrial branches for dyeing, e.g. wool, cotton, nylon, leather, paper, cosmetics, pharmaceuticals, food, plastic and petroleum products (An et al. 2002; Cui et al. 2012; Franciscon et al. 2009a, b; Hamid and Rehman 2009; Koyani et al. 2013; Padamavathy et al. 2003; Somasiri et al. 2006; Swamy and Ramsay 1999; Tony et al. 2009; Younes et al. 2012).

The common usage of dyes causes an increase of their concentration in the environment. The disposal of wastewater with high dye concentrations leads to contamination of surface waters, reduces light penetration and photosynthetic activity and causes oxygen deficiency.

A serious ecological problem is connected with the persistence of dyes, their toxicity, mutagenicity and resistance to biological degradation because of their synthetic origin and complicated molecular structures. 
They are gradually accumulated in the food chain (Azmi et al. 1998; Banat et al. 1996; Forgacs et al. 2004; Franciscon et al. 2009a, b; Hamid and Rehman 2009; Koyani et al. 2013; Pointing and Vrijmoed 2000; Sani and Banerjee 1999; Wong and Yuen 1998). This situation requires the development of an environmentally friendly and economically acceptable treatment technology (Eichlerova et al. 2006; Hamid and Rehman 2009; Hu 2001; Koyani et al. 2013; Tony et al. 2009). Biological treatment based on microbial activity is more attractive than physicochemical methods. Biodegradation is considered an environmentally friendly and cost-effective option (An et al. 2002; Chen et al. 2003; Cui et al. 2012; Franciscon et al. 2009a, b; Wang et al. 2012; Wu et al. 2009; Wu et al. 2012).

Various organisms can remove and even mineralise dyes (bacteria, fungi, algae and plants) (Cui et al. 2012; Franciscon et al. 2009a, b; Hamid and Rehman 2009; Koyani et al. 2013, Srinivasan and Viraraghavan 2010; Tony et al. 2009; Younes et al. 2012). The most important factors that affect the efficiency of biological dye removal are the type of organisms, process conditions (e.g. temperature, oxygen level, $\mathrm{pH}$ and additional available carbon and nitrogen sources) and concentrations and the chemical structures of the dyes (Azmi et al. 1998; Banat et al. 1996; Cui et al. 2012; Franciscon et al. 2009a, b; Forgacs et al. 2004; Hamid and Rehman 2009; Koyani et al. 2013; Padamavathy et al. 2003; Pointing and Vrijmoed 2000; Przystaś et al. 2009; Sani and Banerjee 1999; Saratale et al. 2011; Stolz 2001; Swamy and Ramsay 1999; Tony et al. 2009; Younes et al. 2012; Zabłocka-Godlewska et al. 2009). Dye removal based on microbial activity is widely described. These technologies are based on the biodegradation/ biotransformation of dyes using living bacteria and fungi and the physical sorption on living or dead biomass (An et al. 2002; Chen et al. 2003; Cui et al. 2012; Franciscon et al. 2009a, b; Wang et al. 2012; Wu et al. 2009; Wu et al. 2012).

Single strains of different bacterium taxonomic groups and their co-cultures and mixtures are used in dye removal technologies. The most popular genera of bacteria described in the literature are Pseudomonas, Bacillus, Sphingomonas, Aeromonas, Citrobacter, Escherichia, Desulphovibrio, Proteus, Schewanella, Klebsiella, Alcaligenes, and Streptococcus (An et al. 2002; Cui et al. 2012; Franciscon et al. 2009a, b; Nigam et al. 1996; Saratale et al. 2011; Sharma et al. 2004; Tony et al. 2009; Wang et al. 2012). Klebsiella, which are rod-shaped, non-motile, Gram-negative bacteria, have a thin cell wall that contains approximately $10 \%$ peptidoglycan and outer membrane (contains proteins, phospholipids and lipopolysaccharides). Bacteria of this genus have a polysaccharide capsule and are oxidase negative (Salyers and Whitt 2000; Schlegel 1993). The decolourisation results of azo dyes in aerobic conditions by the Klebsiella pneumoniae strain were described by Wong and Yuen (1998). Cui et al. (2012) reported that a consortium of 13 bacterial strains including 11 isolates of Klebsiella sp. could significantly decolourise azo dyes in aerobic and anaerobic conditions. The decolourisation of azo dyes by Klebsiella pneumoniae was also studied by Zhang et al. (2010), Franciscon et al. (2009b) and Elizalde-Gonzales et al. (2009).

Most existing studies on dye removal concentrate on individual dyes (mostly the azo class) although they are present in wastewater as a mixture. There remains a lack of information about the efficacy of decolourisation of dye mixtures that contain dyes from different groups. In our study, we focused on the removal efficiency of various dyes (azo Evans blue and triphenylmethane brilliant green) individually and in mixture using two different strains from the Klebsiella genera. A notably important part of the decolourisation studies is the assessment of environmental risk, which is connected with the possibility of producing toxic biotransformation products. Our study evaluated the toxicity of biotransformation products on aquatic organisms.

\section{Materials and Methods}

\subsection{Isolation of Bacterial Strains}

The bacteria that were used in the experiment were isolated from the inlet of the wastewater treatment plant in Katowice (Bz4) and the polluted river Leśnica in Wodzisław Ślaski (Rz7) located in south Poland. The wastewater treatment plant in Katowice has a daily flow of approximately $43,000 \mathrm{~m}^{3} \mathrm{day}^{-1}$. According to Polish law (Dz. U. 2012 r. poz.145; Dz. U. Nr257, poz. 1545), Leśnica river is classified as a river with poor ecological status.

The bacteria strains were isolated using the spread plate method on nutrient agar (BTL), which was supplemented with $0.1 \mathrm{~g} \mathrm{l}^{-1}$ of brilliant green. After $72 \mathrm{~h}$ of incubation, a discolouration zone was observed around 
some bacterial colonies, which proved their decolourisation abilities. The colonies with the largest discoloured area, which was measured from the edge of the colony (11 and $18 \mathrm{~mm}$ for Bz4 and Rz7, respectively), were isolated and purified on nutrient agar (BTL) using the streak plate method. Selected strains were classified as Klebsiella planticola (Rz7) and Klebsiella sp. (Bz4) using the API 20E test (Biomerieux).

\subsection{Decolourisation Potential}

In the experiment, the Kimura medium ( $\mathrm{pH}$ 6.8) was used (Zabłocka-Godlewska et al. 2012). Bacterial suspensions for medium inoculation were prepared in physiological salt (the optical density of each suspension was $\sim 15 \times 10^{8} \mathrm{cfu} \mathrm{ml}^{-1}$ ). Then, $0.1 \mathrm{ml}$ of innoculum was added to tubes that contained $10 \mathrm{ml}$ of the medium. Five different dyes (fluorone: Bengal rose (BR), erythrosine (E); triphenylmethane: brilliant green (BG), crystal violet $(\mathrm{CV})$; azo: Evans blue (EB)) in two concentrations $\left(0.05\right.$ and $\left.0.1 \mathrm{~g} \mathrm{l}^{-1}\right)$ were used.

Filter-sterilised dyes were added to tubes with 48-hold bacteria cultures (stationary growth phase). All samples were prepared in triplicate. The samples were incubated at $26^{\circ} \mathrm{C}$ for $144 \mathrm{~h}$. After the experiment ended, the samples were collected and centrifuged $(5000 \mathrm{rpm} /$ $10 \mathrm{~min}$ ), and the supernatant was used for absorbance estimation on a spectrophotometer (UV-Vis Hitachi U-1900). The maximal absorbance was experimentally determined for each dye $(527 \mathrm{~nm}$ for erythrosine, $548 \mathrm{~nm}$ for Bengal rose, $590 \mathrm{~nm}$ for crystal violet, $624 \mathrm{~nm}$ for brilliant green and $606 \mathrm{~nm}$ for Evans blue) (Zabłocka-Godlewska et al. 2012). The percentage of dye removal was calculated according to formula 1 .

$\mathrm{R}=(\mathrm{C}-\mathrm{S} / \mathrm{C}) \times 100 \%$

$\mathrm{R}$-Dye removal (\%)

$\mathrm{C}$-Dye concentration in a control sample ( $\mathrm{mg} \mathrm{l}^{-1}$ )

$\mathrm{S}$-Dye residue concentration in a sample with living/dead bacteria biomass ( $\mathrm{mg}^{-1}$ )

\subsection{Main Experiment}

The dye concentration in the main experiment was determined based on the concentration test. The effect of five different concentrations $(0.01,0.025,0.05,0.075$ and $0.1 \mathrm{~g} \mathrm{l}^{-1}$ ) of Evans blue and brilliant green on the decolourisation effectiveness was estimated. For the dye mixture, an equal proportion (1:1) of brilliant green and Evans blue was used. The effect of six different mixture concentrations $(0.02,0.04,0.06,0.08,0.1$ and $0.12 \mathrm{~g} \mathrm{l}^{-1}$ ) on the decolourisation effectiveness was studied. An identical experiment was performed for the liquid Kimura medium ( $\mathrm{pH}$ 6.8).

Inoculum and dyes were prepared using the method described in Sect. 2.2, except that the inoculum was added to $100-\mathrm{ml}$ flasks that contained $50 \mathrm{ml}$ of Kimura medium. The samples were incubated for 6 days at $26{ }^{\circ} \mathrm{C}$. The samples were collected and centrifuged (5000 $\mathrm{rpm} / 10 \mathrm{~min}$ ), and the supernatant was used to estimate the absorbance. The absorbance was measured on a UV-Vis Hitachi U-1900 at determined wavelengths for Evans blue ( $\lambda$ max, $606 \mathrm{~nm}$ ), brilliant green $(\lambda \max , 624 \mathrm{~nm})$ and the dye mixture $(\lambda \max , 591 \mathrm{~nm})$. The percentage of dye removal was calculated according to formula 1 (Sect. 2.2).

The main experiment was performed using the same method as in our previous study on Pseudomonas strains (Zabłocka-Godlewska et al. 2014). For this part of the experiment, the dye concentrations were selected based on the results of the concentration test $\left(0.05 \mathrm{~g} \mathrm{l}^{-1}\right.$ for Evans blue; $0.1 \mathrm{~g} \mathrm{l}^{-1}$ for brilliant green; $0.08 \mathrm{~g} \mathrm{l}^{-1}$ for the mixture). For the mixture, Evans blue and brilliant green were prepared in a ratio of $1: 1\left(0.04 \mathrm{~g} \mathrm{l}^{-1}\right.$ of BG and $0.04 \mathrm{~g} \mathrm{l}^{-1}$ of EB). Identically to the previous case (Zabłocka-Godlewska et al. 2014), the cultures were incubated in different conditions (static, semistatic and shaken). The shaken samples were shaken on a rotary shaker for $24 \mathrm{~h} \mathrm{day}^{-1}$ (200 rpm); the semistatic samples were shaken with the same speed as the shaken samples every other day. The static samples were not shaken at all. To determine the degree of sorption, autoclaved dead biomass was used.

Samples were taken after 1, 6, 24, 48, 72, 96 and $120 \mathrm{~h}$ of incubation and centrifuged $(5000 \mathrm{rpm} / 10 \mathrm{~min})$, and the supernatant was used to estimate the absorbance using a UV-Vis spectrophotometer Hitachi U-1900. The percentage of dye removal was calculated as previously according to formula 1 .

\subsection{Toxicity Evaluation}

Daphnia magna (OECD 202) was used to evaluate the zootoxicity. The phytotoxicity test was performed according to the OECD Lemna sp. growth inhibition test no. 221. All tests were performed in quadruple. After the estimation of $\mathrm{EC}_{50}$, the acute toxicity unit (TUa) was 
calculated (Zabłocka-Godlewska et al. 2014), which allowed us to establish a toxicity class. According to ACE 89/BE 2/D3 Final Report Commission EC, TUa $<$ 0.4 corresponds to class I (non-toxic), $0.4 \leq \mathrm{TUa}<1.0$ corresponds to class II (low toxicity), $1.0 \leq \mathrm{TUa}<10$ corresponds to class III (toxic), $10 \leq \mathrm{TUa} \leq 100$ corresponds to class IV (high toxicity), and TUa $>100$ corresponds to class V (extremely toxic).

\section{Results and Discussion}

\subsection{Decolourisation Potential}

This study concentrates on the effectiveness of dye decolourisation using two Klebsiella strains isolated from two different sites. Bacteria from the genus Klebsiella, which is part of the family "Enterobacteriaceae", are opportunist pathogens that are responsible for human nosocomial infections. These infections are mainly caused by two strains: Klebsiella pneumoniae and Klebsiella oxytoca (Jonas et al. 2004; Podschun et al. 2000; Westbrook et al. 2000). In this experiment, we used Klebsiella planticola and Klebsiella sp. Isolated from the river, $K$. planticola (percentage of identification by API $20 \mathrm{E} \mathrm{id} \%=99 \%$ ) is restricted to aquatic, soil and botanic environments and rarely reported as the cause of human infections. The identification of Klebsiella sp. (isolated from the inlet of a wastewater plant) was more complicated. The numerical code and additional tests identify two strains: K. planticola and K. terrigena. Both strains are more related to each other than to K. pneumoniae. The strain $K$. terrigena, like $K$. planticola, is an environmental strain that is mainly isolated from soil and water but rarely from humans or clinical specimens. Literature data shown low virulence of the aforementioned Klebsiella strains (Boye and Hansen 2003; Jonas et al. 2004; O' Connell et al. 2010; Olson et al. 2013; Podschun et al. 2000; Westbrook et al. 2000; Zlotnikov et al. 2001). Their usage in bioremediation processes appears relatively safe for the environment and public health.

The results of the decolourisation potential test (Table 1) show the differences between the abilities of both tested Klebsiella strains. Fluorone dyes (erythrosine, Bengal rose) and azo dye (Evans blue) were removed by both strains at comparable levels (from $86 \%$ at high concentration to $100 \%$ at low concentration). Differences were observed in the removal effectiveness of triphenylmethane dyes (brilliant green and crystal violet) at higher concentration $\left(0.1 \mathrm{~g} \mathrm{l}^{-1}\right)$. Bz4 removed up to $81.4 \%$ of $\mathrm{BG}$ and $59.8 \%$ of $\mathrm{CV}$, whereas the strain Rz7 removed more than $98 \%$ of both dyes. As observed, the decolourisation potential is related to the strain, dye concentration and structure, which was also noticed in other studies. Our obtained results for two Pseudomanas strains (Zabłocka-Godlewska et al. 2012) proved that the dye structure and concentration and the site of the strain isolation affect the decolourisation effectiveness. The Pseudomonas fluorescens strain Sz6 almost completely removed TPM dyes (crystal violet and brilliant green) regardless of the dye concentration, whereas the $P$. fluorescens strain SDz3 removed approximately $90 \%$ of these dyes only at the concentration of $0.05 \mathrm{~g} \mathrm{l}^{-1}$. The removal results of azo Evans blue for Klebsiella strains (Table 1) were comparable with the results of Zabłocka-Godlewska et al. (2012) for the Pseudomonas strain Sz6, but they were much lower for the strain SDz3 $(<73 \%)$. Fluorone dyes were more than $85 \%$ removed (Table 1) by both tested Klebsiella strains, whereas in our previous study on $P$. fluorescens (Zabłocka-Godlewska et al. 2012), the strain SDz3 removed them at comparable levels and the strain Sz6 removed less than $55 \%$. Alhassani et al. (2007) proved that Brevibacillus sp. isolated from Coomassie Brilliant Blue (triphenylmethane dye) polluted soil had high decolourisation potential. Among eight tested dyes from different groups, only three were not removed by this strain. Wu et al. (2009) tested the decolourisation potential of TPM and azo dyes by Pseudomonas otitidis WL13 when different dye concentrations were present in the samples. The tested strain showed the highest decolourisation capability against TPM malachite green and brilliant green. Both dyes were removed by more than $95 \%$, even at a concentration of $500 \mu \mathrm{mol} \mathrm{l}^{-1}$. Crystal violet was completely removed at concentrations of up to $20 \mu \mathrm{mol} \mathrm{l}^{-1}, 65.5 \%$ removed at a concentration of $200 \mu^{m o l ~} \mathrm{~m}^{-1}$ and only $13.2 \%$ removed at a concentration of $500 \mu \mathrm{mol} \mathrm{l}^{-1}$. TPM were better removed than azo dyes, which is related to the more complex structure of dyes from the azo class. In the study of Wu et al. (2009), the dyes with the monoazo group were better removed than diazo. Cui et al. (2012) tested the effectiveness of azo dye removal using a consortium composed of different Klebsiella strains. Eriochrome black $\mathrm{T}$ and methyl orange were less than $80 \%$ removed after $16 \mathrm{~h}$, but the other four azo dyes were completely removed. Zhang et al. (2010) tested eight different bacteria consortia for the decolourisation 
Table 1 Results of the decolourisation potential test

\begin{tabular}{lllll}
\hline Dye removal (\%) & \multicolumn{2}{l}{ Strain Bz4 } & \multicolumn{2}{l}{ Strain Rz7 } \\
\cline { 2 - 5 } & \multicolumn{2}{l}{ Initial dye concentration } & & \\
\cline { 2 - 5 } & $0.05 \mathrm{~g} \mathrm{l}^{-1}$ & $0.1 \mathrm{~g} \mathrm{l}^{-1}$ & $0.05 \mathrm{~g} \mathrm{l}^{-1}$ & $0.1 \mathrm{~g} \mathrm{l}^{-1}$ \\
\hline Erythrosine & $99.02 \pm 1.62$ & $86.0 \pm 0.5$ & $100.66 \pm 0.81$ & $93.9 \pm 1.0$ \\
Bengal rose & $100.08 \pm 1.96$ & $100.00 \pm 0.0$ & $100.02 \pm 1.11$ & $93.3 \pm 0.92$ \\
Crystal violet & $98.8 \pm 1.73$ & $59.8 \pm 0.44$ & $99.00 \pm 0.49$ & $98.6 \pm 0.43$ \\
Brilliant green & $100.55 \pm 0.62$ & $81.4 \pm 0.4$ & $100.07 \pm 0.13$ & $98.0 \pm 0.2$ \\
Evans blue & $98.79 \pm 1.81$ & $86.01 \pm 0.81$ & $99.52 \pm 0.34$ & $90.5 \pm 0.4$ \\
\hline
\end{tabular}

of 14 azo dyes. Unlike the hydroxyl group, the presence of carboxyl and sulfo groups significantly increased the azo dye biodegradability.

\subsection{Main Experiment—Decolourisation of Dyes}

\subsubsection{Effect of the Dye Concentration on the Effectiveness of Dye Decolourisation}

The dye concentrations for the main experiment were selected based on the concentration test (Fig. 1a-c). When the brilliant green concentration increased to $0.05 \mathrm{~g}^{-1}$ and more, the decolourisation effectiveness of both tested strains (Fig. 1a) decreased. After 6 days, the removal of BG in a sample with a concentration of $0.05 \mathrm{~g} \mathrm{l}^{-1}$ was $74.96 \%$ for the strain Bz4 and $68.22 \%$ for Rz7. The increase in concentration to $0.075 \mathrm{~g} \mathrm{l}^{-1}$ resulted in further decrease of dye decolourisation effectiveness (62.92 and $49.91 \%$, respectively). At the highest concentration of $\mathrm{BG}\left(0.1 \mathrm{~g}^{-1}\right)$, the obtained dye removal was $59.36 \%$ for Bz4 and $47.16 \%$ for Rz7. Higher dye concentrations in the sample are more toxic for bacteria. The strain tolerance to xenobiotics is related to their individual properties (e.g. the sorption potential which is connected with the cell wall structure, presence of a capsule or specific enzymatic system). The obtained results in our previous study (Zabłocka-Godlewska et al. 2014) for two Pseudomonas strains showed better tolerance to higher BG concentrations than Klebsiella strains (Fig. 1a). The effect of the initial dye concentration on the dye removal effectiveness was documented by $\mathrm{Wu}$ et al. (2012). For Shewanella oneidensis MR-1, the decolourisation ability gradually decreases with the increase in dye concentration. The removal of brilliant green and malachite green (TPM) by Citrobacter sp. was studied by An et al. (2002). After $1 \mathrm{~h}$, both triphenylmethane dyes were completely removed at concentrations of 5 and $10 \mu \mathrm{M}$. An increase in concentration to $100 \mu \mathrm{M}$ decreased the decolourisation to $\sim 82 \%$ and further increase in dye concentration resulted in further decrease of the removal level.

Evans blue had worse decolourisation test results than brilliant green (Fig. 1b). A similar effect was found for the previously studied Pseudomonas strains, particularly in the case of SDz3 (Zabłocka-Godlewska et al. 2012, 2014). Diazo Evans blue appears to be a more difficult substrate for the studied strains. After 6 days of experiment in the sample with the lowest concentration $\left(0.01 \mathrm{~g} \mathrm{l}^{-1}\right)$, the dye removal reached $90.72 \%$ for Bz4 and $90.34 \%$ for Rz7 strain. In addition, in this case, at higher dye concentration, the decolourisation effectiveness decreased. In samples with $0.05 \mathrm{~g} \mathrm{l}^{-1}$ of EB, the removal was $54.56 \%$ for Bz4 and $47.07 \%$ for Rz7. At the highest concentration $\left(0.1 \mathrm{~g} \mathrm{l}^{-1}\right)$, the dye removal was only 32.14 and $29.17 \%$ for Bz4 and Rz7, respectively. An et al. (2002) studied the decolourisation of diazo dye Congo Red using Citrobacter sp. An increase in concentration to 50 and $100 \mu \mathrm{M}$ resulted in a strong decrease in decolourisation efficacy to 28 and $26 \%$, respectively. At the concentration of $2000 \mu \mathrm{M}$, no decolurisation of Congo Red was observed. Isik and Sponza (2003) conducted an experiment with Escherichia coli and reached 100 and $85 \%$ removal of Congo Red when the dye concentration varied between 250 and $2500 \mathrm{mg} \mathrm{l}^{-1}$, whereas $55 \%$ removal was obtained for $3000 \mathrm{mg} \mathrm{l}^{-1}$. Cui et al. (2012) presented the results of methyl red removal using a consortium of bacteria (mostly consisted of Klebsiella strains). In anaerobic conditions, the decolourisation was almost complete (94-98\%) after 10 and $20 \mathrm{~h}$ when the dye concentration was 200 and $500 \mathrm{mg} \mathrm{l}^{-1}$, respectively. In aerobic conditions, the consortium required $40 \mathrm{~h}$ to 
Fig. 1 Influence of brilliant green (a), Evans blue (b) and the dye mixture (c) concentration on the effectiveness of their removal
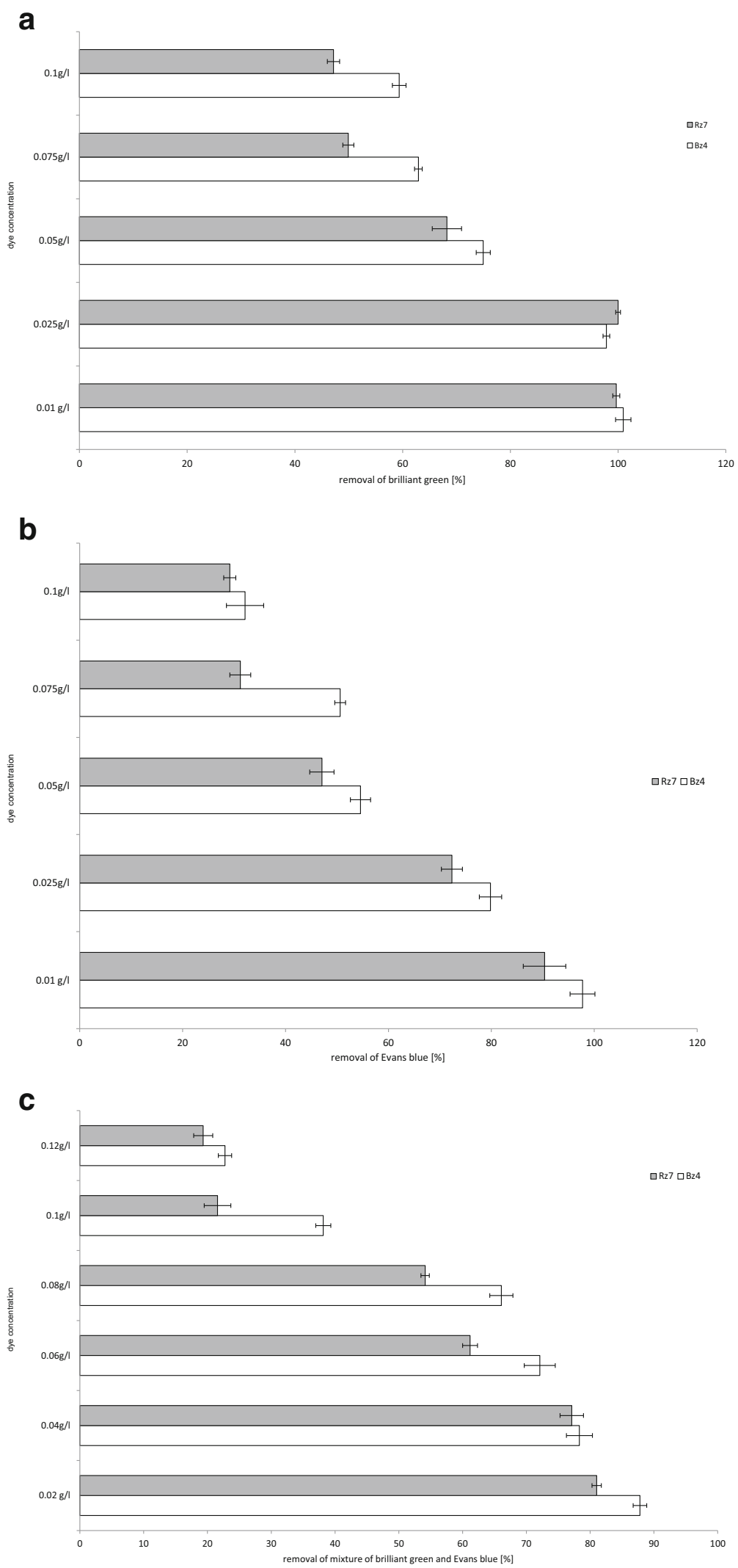
remove $95 \%$ of $200 \mathrm{mg} \mathrm{l}^{-1} \mathrm{MR}$ and $48 \mathrm{~h}$ to remove $70 \%$ at a concentration of $500 \mathrm{mg} \mathrm{l}^{-1}$.

A potential decolourisation test was performed for a mixture of both dyes, which shows that at the lowest tested concentration, the removal was less than $90 \%$ when the single dyes were almost completely removed (Fig. 1c). At a concentration of $0.08 \mathrm{~g} \mathrm{l}^{-1}$, the dye removal was $66.08 \%$ by Bz4 and $54.13 \%$ by Rz7. The decolourisation effectiveness of both strains significantly decreased when the dye concentration was $0.1 \mathrm{~g} \mathrm{l}^{-1}$ (38.16 and $21.57 \%$, respectively). The effect of the dye mixture concentration on the decolourisation effectiveness is not well documented in the literature. A similar tendency was found for Pseudomonas strains that were previously studied (Zabłocka-Godlewska et al. 2014). Apart from our previous work, there is a lack of information about the effect of the concentration when the mixture of dyes is composed of dyes of different classes. Vijaykumar et al. (2007) studied the decolourisation efficacy of Kerstersia sp. for mixtures of three azo dyes (Amaranth, Fast red E, Ponceau S) at five concentrations. The concentrations of 200 $800 \mathrm{mg}^{-1}$ were completely removed, but the required time for their removal was longer when the dye content increased. Based on the results of our test, different concentrations were used for further studies: $0.1 \mathrm{~g} \mathrm{l}^{-1}$ of brilliant green, $0.05 \mathrm{~g} \mathrm{l}^{-1}$ of Evans blue and $0.08 \mathrm{~g} \mathrm{l}^{-1}$ of mixture $\left(0.04 \mathrm{~g} \mathrm{l}^{-1}\right.$ of BG and $0.04 \mathrm{~g} \mathrm{l}^{-1}$ of $\left.\mathrm{EB}\right)$.

\subsubsection{Effect of the Growth Conditions on the Delcolourisation Effectiveness-Main Experiment}

The main experiment was performed under static, semistatic and shaken conditions. The sorption was estimated using bacteria dead biomass. The usage of dead biomass allows an approximate determination of the biomass sorption properties with the exclusion of biotransformation and/or biodegradation. The mechanism of microbial decolourisation occurs from adsorption, enzymatic degradation or a combination of both. The obtained results using the samples with dead and living biomass must be compared to specify the participation of both mechanisms in dye decolourisation.

Brilliant green was better removed by the strain Rz7 than Bz4 regardless of the culture conditions (Fig. 2a-c). In the sample with Rz7, almost complete decolourisation was obtained under static conditions after $24 \mathrm{~h}$. Identical levels of dye removal in semistatic and shaken conditions were obtained after $48 \mathrm{~h}$ of experiment. The brilliant green removal by the strain $\mathrm{Bz} 4$ in static conditions after $24 \mathrm{~h}$ was $81.14 \%$, and all dye was removed after $96 \mathrm{~h}$ of experiment. Worse results for this strain were noticed in the semistatic condition and particularly in the shaken condition. Shaking increases the dissolved oxygen concentration, evenly distributes it throughout the sample and transfers it between the cells and the medium. In the shaken samples, the bacteria have better contact with the dyes, which should positively affect decolourisation. The previously presented results note that shaking negatively affects the dye removal rate, particularly during first hours of the experiment. These results confirm that facultative anaerobic strains of Klebsiella prefer lower oxygen concentration. Finally (at $120 \mathrm{~h}$ ), all BG was removed by the strain Bz4 in the static samples, $93.56 \%$ in the semistatic samples and $79.85 \%$ in the shaken samples. It should be noted that despite the end results, the strain Bz4 has high effectiveness of BG removal (approximately $60 \%$ ) after the first hour of the experiment regardless of the process conditions, which is related to the high sorption potential of this strain. The biosorption capacity of microorganisms depends on the composition of the cell wall (heteropolysaccharides and lipids). These components contain different functional groups (amino, carboxyl, hydroxyl, phosphate and other charged groups), which cause strong attractive forces between the dye molecule and the bacteria cell wall. The results obtained for the dead biomass (Fig. 3) and observed intensive tint of living biomass confirm this mechanism. After $1 \mathrm{~h}$ of the experiment, the dead biomass of Bz4 sorbed almost $50 \%$ of BG (and $70 \%$ after $120 \mathrm{~h}$ ), whereas the strain Rz7 removed less than $20 \%$. These results suggest a higher contribution of biodegradation processes in $\mathrm{BG}$ decolourisation by the strain Rz7.

The pathways of bacterial biodegradation of triphenylmethane dyes remain not well documented. There is lack of information about the dye metabolic pathway for the genus Klebsiella. Jang et al. (2005) studied Citrobacter sp. strain KCTC18061P which belongs, the same as Klebsiella, to Enterobacteriaceae family. The reported strain had a high decolourisation potential of triphenylmethane dyes. The enzyme that is responsible for the decolourisation abilities is triphenylmethane reductase (TMR). Wang et al. (2012) proposed a pathway of methyl green (MG) degradation by Exiguobacterium sp. MG2 under shaking conditions. The mechanisms of this dye degradation were related to the activity of TMR 
Fig. 2 Percentage of removal of the dyes in the static (a), semistatic (b) and shaken samples (c)

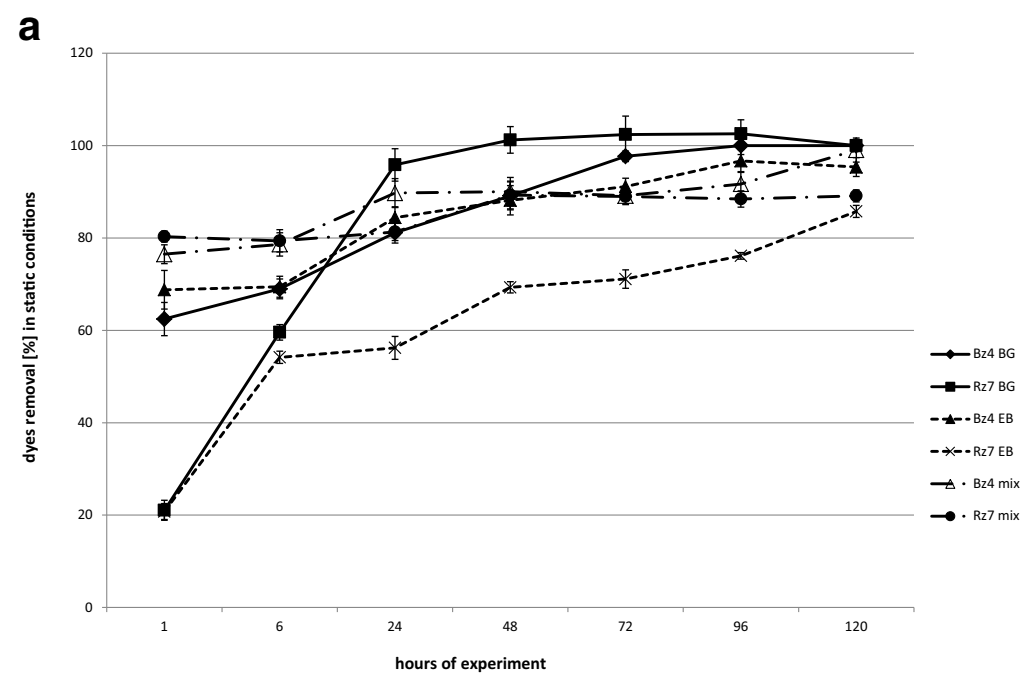

b

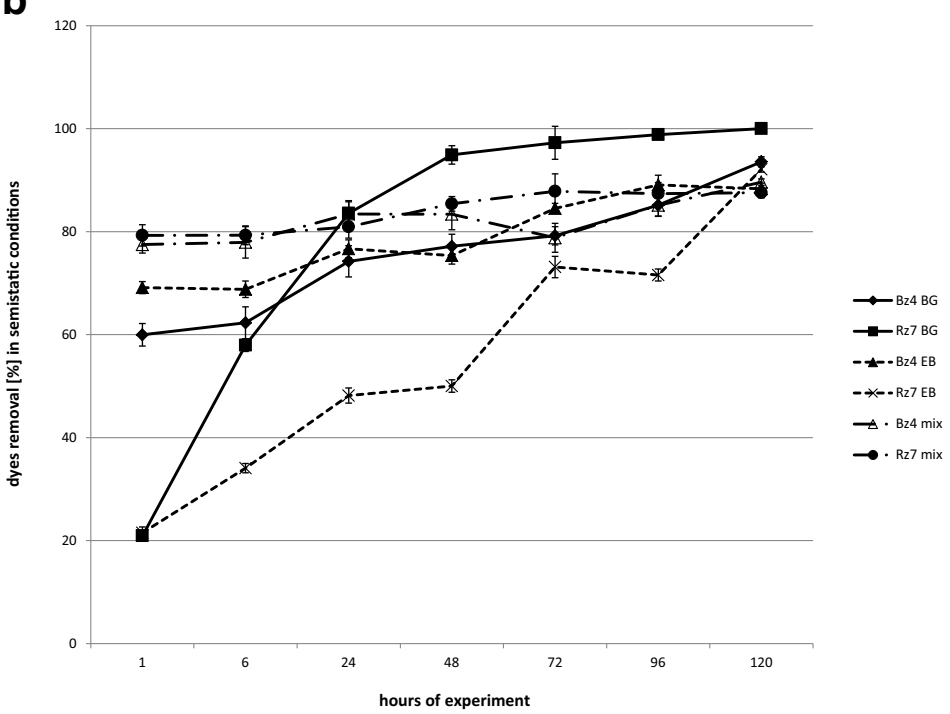

C

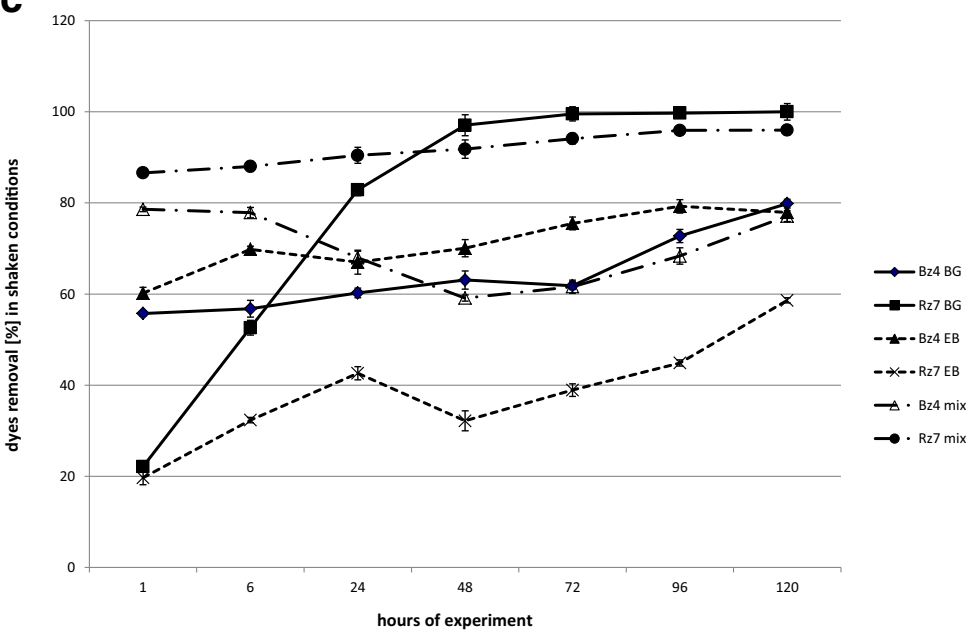




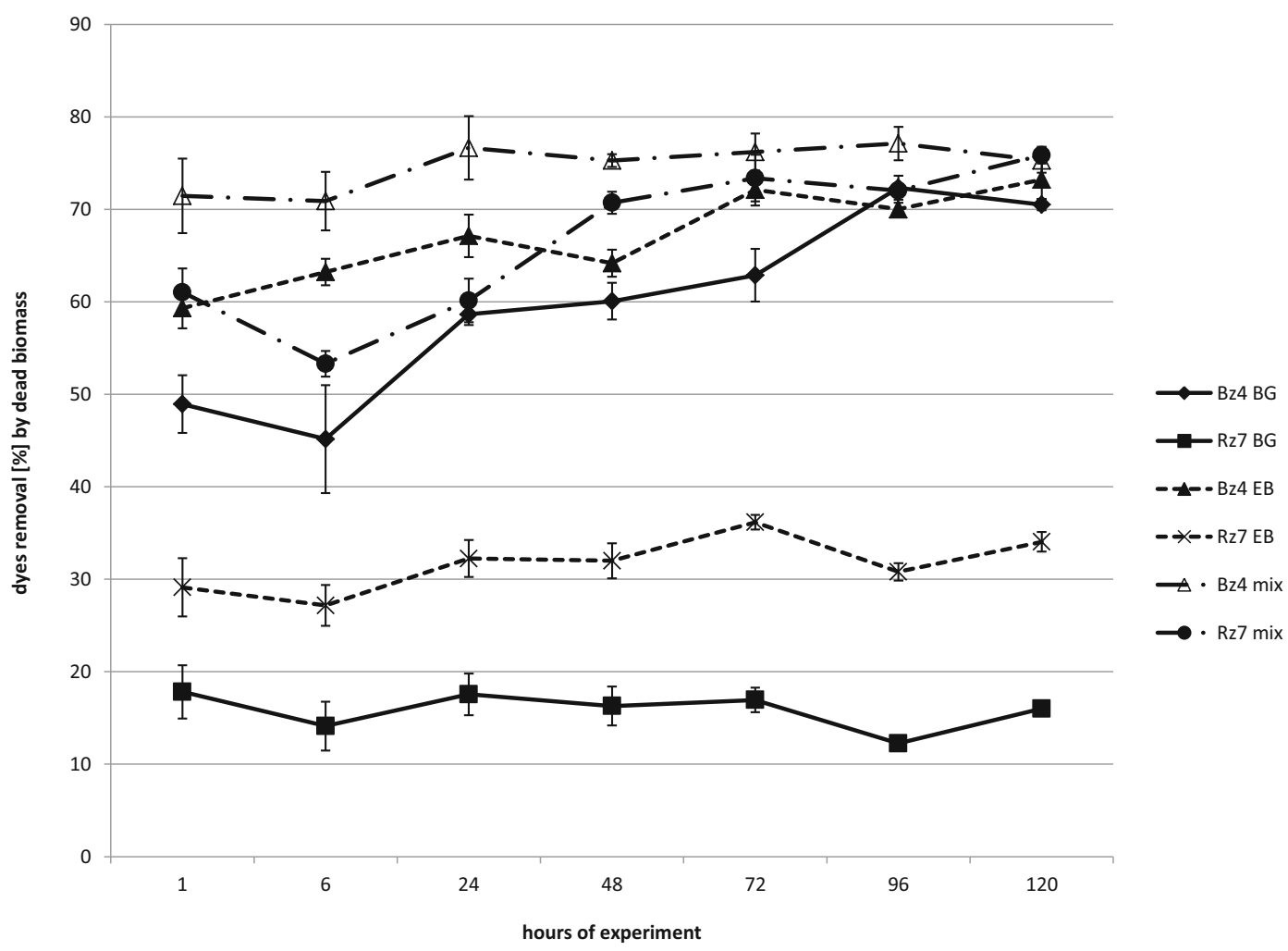

Fig. 3 Removal of the dyes in samples with dead biomass

and cytochrome P450. The first step was connected with the TMR activity, which catalyses MG into its leucoform, which is later transformed by cytochrom P450. The decolourisation efficiency was more than $90 \%$ after $3 \mathrm{~h}$ of experiment for all tested concentrations (1000-2500 mg ${ }^{-1}$ ). Wang et al. (2011) proved that during the malachite green decolourisation by Achromobacter xolosoxidans MG1, extracellular enzymes and some heat resistance extracellular compounds were involved. The incubation conditions (static and shaking) did not significantly affect the dye removal. The decolourisation of crystal violet (TPM dye) at a concentration of $30 \mu \mathrm{mol} \mathrm{l}^{-1}$ was studied by Wu et al. (2009). After $36 \mathrm{~h}$, the decolourisation by Pseudomonas otitidis was approximately $20 \%$ under static conditions and less than $15 \%$ under shaking conditions. For this strain, the dye adsorption on biomass was observed. In other experiment presented by the same authors, crystal violet was almost completely removed in shaking conditions after $12 \mathrm{~h}$ at concentrations of up to $100 \mu \mathrm{mol} \mathrm{l}{ }^{-1}$. An et al. (2002) studied the decolourisation of crystal violet at a concentration of $20 \mathrm{mg} \mathrm{l}^{-1}$ under various conditions. The best results were achieved in the shaken samples. After $4 \mathrm{~h}$ of incubation, almost complete removal was observed in the shaking samples, whereas it was less than $40 \%$ in the static samples. After $16 \mathrm{~h}$, complete removal was observed regardless of the process conditions.

Both Klebsiella strains decolourised Evans blue with higher efficacy in static samples (Fig. 2a) than in shaken samples (Fig. 2c). In static and shaken samples, the strain $\mathrm{Bz} 4$ had better final decolourisation results (95.36 and $77.93 \%$ removal, respectively) than the strain Rz7 (85.76 and $58.62 \%$, respectively). The final removals in semistatic conditions for both strains were at similar levels ( $90 \%$ ) (Fig. 2b). Similar to the aforementioned brilliant green results, shaking negatively affects the Evans blue removal rate, particularly during the first hours of the experiment. Similar to the experiment with BG, the strain Bz4 removed $60-70 \%$ of EB in the first hour of the test regardless of the culture conditions. As previously mentioned, these results and the results obtained in the samples with dead biomass confirm the high contribution of sorption in the EB removal by the strain Bz4, particularly at the beginning of the decolourisation process. The dead biomass of the 
strain Bz4 finally adsorbed up to $73.23 \%$ of dye, whereas Rz7 adsorbed only $34.05 \%$. In our previous study with Evans blue and Pseudomonas strains, the effect of agitation on the decolourisation effectiveness was also negative. In static conditions, almost complete decolourisation was obtained by the strain Sz6 after $48 \mathrm{~h}$, whereas in shaking conditions, it was less than $70 \%$ (Zabłocka-Godlewska et al. 2012). In case of another Pseudomonas strain (SDz3), at the end of the experiment, the results were comparable.

The effects of oxygen and agitation on the azo dye decolourisation are widely described (Van der Zee and Villaverde 2005; Saratale et al. 2010; Saratale et al. 2011; Pearce et al. 2003). It is reported that during the bacterial decolourisation of azo dyes, both oxidative and reductive enzymes play a role (Pearce et al. 2003; Saratale et al. 2011). The first step of azo dye decolourisation is reduction by azoreductases, which are almost exclusively anaerobic in nature, so their activity is higher under anaerobic conditions, which is related to the competition for substrate between oxygen and azoreductases. However, a small amount of oxygen is required for the oxidative enzymes that are involved in the degradation of azo dyes. Franciscon et al. (2009a, b) studied the decolourisation of four azo dyes by Staphylococcus arlettae and Klebsiella sp. under microaerophilic and aerobic conditions. There was no significant difference in the final dye removal regardless of the conditions. Complete removal or almost complete removal ( $\sim 95 \%)$ of all tested dyes was obtained for the tested Klebsiella strain after $168 \mathrm{~h}$ regardless of the incubation conditions. Elizalde-Gonzales et al. (2009) studied the degradation of immobilised azo dyes by Klebsiella sp. UAP-b5. After $48 \mathrm{~h}$, effective decolourisation of the dye BB41 was observed in anaerobic conditions. Cui et al. (2012) tested the decolourisation of six azo dyes in various conditions (aerobic and anaerobic). The decolourisation results depended on the dye structure, but in the cases of methyl orange, orange 1 and Congo Red, the final decolourisation was higher under anaerobic conditions, which confirms the observed tendency in our studies.

The dye mixture was significantly removed by both tested strains from the beginning of the experiment (Fig. 2a-c). After $1 \mathrm{~h}$, both strains decolourised the mixture by $\sim 80 \%$ in all conditions. Finally, the living biomass of the strain Rz7 removed $89.12 \%$ in the static, $87.58 \%$ in the semistatic and $96 \%$ in the shaken conditions. The strain Bz4 removed 99.04, 89.62 and $77.12 \%$, respectively. High sorption of the dye mixture was observed for both tested strains. The dead biomass of the strain Bz4 adsorbed more than $70 \%$ after $1 \mathrm{~h}$, whereas the dead biomass of the strain Rz7 adsorbed approximately $60 \%$. Finally, both strains adsorbed approximately $75 \%$ of the dye mixture (Fig. 2c).

The UV-Vis scan of the dyes, which was shown in our previous publication (Zabłocka-Godlewska et al. 2014), and results obtained with the dead biomass, suggests that the dyes in the mixture interacted with one another. The structure of the dyes in the mixture was most likely changed, which confirms the shift in wavelength of the maximal absorbance compared to those of the single dyes. This interaction may affect the mixture properties. High adsorption of single dyes by the strain Bz4 was observed, whereas the strain Rz7 did not adsorb the tested dyes at such a high level. When the dyes were used in the mixture, the adsorption by both tested strains was significant. The mixture was finally removed by 75.28 and $75.86 \%$ by the dead biomass of Bz4 and Rz7, respectively. Such high adsorption by the dead biomass of the strain Rz7 was observed from the beginning of the experiment $(61.03 \%$ after $1 \mathrm{~h})$, whereas the single-dye adsorption was below $30 \%$. This result confirms the changes of dye structure in the mixture. Differences in decolourisation of the dye mixture and single dyes were also observed for fungal strains, which were studied by Przystaś et al. (2013).

It is necessary to mention that the dyes in the prepared mixture belong to different classes. Most studies concentrated on one group of dyes. Saratale et al. (2010) studied the decolourisation of azo dye mixtures under static conditions by a consortium of Proteus vulgaris and Micrococcus glutamicus. After $72 \mathrm{~h}$, a mixture of three dyes was $86 \%$ removed, the second mixture was $92 \%$ removed, and a mixture of six dyes was $74 \%$ removed. Jadhav et al. (2010) showed that the textile effluent was completely decolourised in static conditions after $48 \mathrm{~h}$ by a bacterial consortium (two Pseudomonas strains). One of the strains in this consortium was previously studied by Kalyani et al. (2009). A mixture of ten azo dyes was removed by the strain Pseudomonas sp. SUK1 by approximately $25 \%$ after $4 \mathrm{~h}$ and approximately $90 \%$ after $24 \mathrm{~h}$ in static conditions. As observed, all studies with dye mixtures were only performed in static conditions, which were recommended for azo dye removal. 


\subsection{Toxicity Evaluation}

High decolourisation effectiveness by the living biomass of Bz4 corresponded with the decrease in toxicity to Daphnia magna (from toxicity class IV to class III for $\mathrm{EB}$, from V to IV for BG and from V to III or IV for the dye mixture). In case of the strain Rz7, the decrease in zootoxicity was only noticed in samples with single dyes (decrease of one class of toxicity) and the mixture that was incubated in shaken conditions (Table 2). The biological transformation of dyes by both Klebsiella strains leads to the formation of less toxic products than dyes. The participation of transformation processes in decreasing the toxicity confirms the following obtained results for the samples with dead biomass.

Despite the high effectiveness of adsorption on the dead biomass of the strain $\mathrm{Bz} 4$, the decrease of zootoxicity was only observed in the samples with BG. In the samples with Rz7, the zootoxicity only decreased for EB. In other samples with single dyes and their mixture, the zootoxicity remained constant (Table 2). The obtained results for EB are comparable with those presented in our previous study (ZabłockaGodlewska et al. 2012). The zootoxicity of Evans blue decreased for the tested Pseudomonas strain SDz3 regardless of the process conditions. Only in the case of

Table 2 Results of the toxicity tests

\begin{tabular}{|c|c|c|c|c|c|c|c|c|}
\hline \multirow[t]{2}{*}{ Strain } & \multirow[t]{2}{*}{ Culture conditions } & & \multicolumn{3}{|c|}{ Daphnia magna } & \multicolumn{3}{|l|}{ Lemna minor } \\
\hline & & & $\mathrm{EC}_{50}$ & TUa & Toxicity class & $\mathrm{EC}_{50}$ & TUa & Toxicity class \\
\hline \multirow[t]{12}{*}{$\mathrm{Bz} 4$} & \multirow[t]{3}{*}{ Static } & EB & $30.03 \pm 2.07$ & 3.33 & III & $35.7 \pm 1.96$ & 2.80 & III \\
\hline & & BG & $6.09 \pm 0.27$ & 16.42 & IV & $41.49 \pm 0.46$ & 2.41 & III \\
\hline & & Mix & $14.83 \pm 0.19$ & 6.74 & III & $18.76 \pm 0.79$ & 5.33 & III \\
\hline & \multirow[t]{3}{*}{ Semistatic } & EB & $21.41 \pm 1.08$ & 4.67 & III & $23.04 \pm 0.69$ & 4.34 & III \\
\hline & & BG & $2.64 \pm 0.17$ & 37.9 & IV & $19.23 \pm 1.08$ & 5.2 & III \\
\hline & & Mix & $11.98 \pm 0.27$ & 8.35 & III & $21.88 \pm 1.44$ & 4.57 & III \\
\hline & \multirow[t]{3}{*}{ Shaken } & EB & $13.64 \pm 0.70$ & 7.33 & III & $6.25 \pm 1.1$ & 16.00 & IV \\
\hline & & BG & $2.10 \pm 0.14$ & 47.58 & IV & $15.50 \pm 1.1$ & 6.45 & III \\
\hline & & Mix & $9.63 \pm 1.14$ & 10.38 & IV & $23.58 \pm 6.20$ & 4.24 & III \\
\hline & \multirow[t]{3}{*}{ Dead biomass } & EB & $2.31 \pm 0.09$ & 43.29 & IV & $13.64 \pm 1.14$ & 7.33 & III \\
\hline & & BG & $24.15 \pm 1.10$ & 4.14 & IV & $21.37 \pm 1.1$ & 4.68 & III \\
\hline & & Mix & n.d. & n.d. & $\mathrm{V}$ & $10.63 \pm 1.2$ & 9.41 & III \\
\hline \multirow[t]{12}{*}{ Rz7 } & \multirow[t]{3}{*}{ Static } & $\mathrm{EB}$ & $39.53 \pm 2.50$ & 2.53 & III & $22.52 \pm 0.46$ & 4.44 & III \\
\hline & & BG & $1.15 \pm 0.17$ & 86.957 & IV & $20.70 \pm 0.51$ & 4.83 & III \\
\hline & & Mix & n.d. & n.d. & $\mathrm{V}$ & $5.71 \pm 0.27$ & 17.5 & IV \\
\hline & \multirow[t]{3}{*}{ Semistatic } & EB & $62.50 \pm 0.09$ & 1.6 & III & $16.81 \pm 1.14$ & 5.95 & III \\
\hline & & BG & $1.33 \pm 0.02$ & 75.05 & IV & $20.75 \pm 0.95$ & 4.82 & III \\
\hline & & Mix & n.d. & n.d. & $\mathrm{V}$ & $64.10 \pm 4.23$ & 1.56 & IV \\
\hline & \multirow[t]{3}{*}{ Shaken } & EB & $75.19 \pm 3.20$ & 1.33 & III & $25.00 \pm 1.7$ & 4.00 & III \\
\hline & & BG & $3.67 \pm 0.20$ & 27.22 & IV & $16.81 \pm 0.7$ & 5.95 & III \\
\hline & & Mix & $9.35 \pm 1.1$ & 10.7 & IV & $4.40 \pm 1.1$ & 22.73 & IV \\
\hline & \multirow[t]{3}{*}{ Dead biomass } & EB & $37.45 \pm 1.80$ & 2.67 & III & $22.78 \pm 1.50$ & 4.39 & III \\
\hline & & BG & $0.85 \pm 0.10$ & 117.64 & V & $25.45 \pm 0.52$ & 3.93 & III \\
\hline & & Mix & n.d. & n.d. & $\mathrm{V}$ & $7.81 \pm 1.10$ & 12.80 & IV \\
\hline \multirow[t]{3}{*}{ Controls } & & EB & $9.43 \pm 0.22$ & 10.62 & IV & $22.22 \pm 2.10$ & 4.5 & III \\
\hline & & BG & $0.98 \pm 0.07$ & 102 & $\mathrm{~V}$ & $3.07 \pm 0.52$ & 32.58 & IV \\
\hline & & Mix & $0.92 \pm 0.15$ & 108.7 & V & $1.20 \pm 0.01$ & 83.3 & IV \\
\hline
\end{tabular}

n.d. not detected 
the strain Sz6, the zootoxicity increased in static conditions. In the samples with dead biomass, the toxicity increased. Staphylococcus arlettae decolourisation ability and zootoxicity of the end-products were studied by Franciscon et al. (2009a). They noticed a lack of zootoxicity in aerobic conditions and significant decrease in microaerophilic samples. These authors tested the decolourisation of the same azo dyes by Klebsiella (Franciscon et al. 2009b) and observed a decrease in mortality of Daphnia magna for all four tested dyes in aerobic conditions and for three of them in microaerophilic conditions. For Direct Blue 71, higher mortality was observed in the microaerophilic samples. The authors suggested that it was related to the higher amount of aromatic amines that were produced during the biodegradation of this triazo dye. Higher zootoxicity was observed in microaerophilic samples, which was related to the accumulation of aromatic amines that were produced in the anaerobic first stage of the bacterial azo dye decolourisation process. The zootoxicity of the decolourisation products of brilliant green was examined in our previous study (Przystaś et al. 2012). In all samples regardless of incubation conditions, the zootoxicity decreased. In the samples with living bacterial biomass, the toxicity even decreased from class $\mathrm{V}$ to class III.

The phytotoxicity was tested on Lemna minor. In the samples with EB, no change in toxicity was observed, and in the shaken samples with Bz4, the toxicity increased from class III to class IV (Table 2). In other samples, the phytotoxicity decreased. In our previous study (Przystaś et al. 2012), an identical situation (no change in toxicity) was noticed for the strain Burkholderia cepacia. For the Pseudomonas strains (Zabłocka-Godlewska et al. 2012), the phytotoxicity only decreased in the static and semistatic samples. In other samples, no change was noticed. The brilliant green removal by Klebsiella strains decreases the phytotoxicity (from IV to III; Table 2). These results contradict our previous study (Przystaś et al. 2012), where the decrease was only observed in the sample with Chryseomonas luteola in static conditions. The phytotoxicity of the dye mixture only decreased for the strain $\mathrm{Bz} 4$ regardless of the modifications of decolourisation conditions. High decolourisation effectiveness by Rz7 had no significant effect on the change in phytotoxicity class (Table 2). The phytotoxicity results obtained for the dye mixture suggest a significant effect of the sorption properties of the strain that is used. In the case of the strain Bz4, which has a strong sorption capacity, the phytotoxicity decreased. In case of the strain Rz7, which is characterised by weaker sorption properties, the phytotoxicity remained unchanged, but the TUa value decreased. The obtained results with dead biomass confirm that the adsorption on biomass may strongly reduce the phytotoxicity of the dye mixture. The decrease in phytotoxicity was only observed in samples with the strain Bz4, which has a high adsorption capacity. The phytotoxicity of TPM methyl red decolourisation products was tested by Cui et al. (2012). Regardless of the process conditions (aerobic and anaerobic), the phytotoxicity decreased. In comparison with the control (no germination), after decolourisation, 90 and $70 \%$ of Brassica pekinensis seed germination was observed in aerobic and anaerobic samples, respectively. Wu et al. (2012) used Shewanella oneidensis to decolourise TPM aniline blue. The decrease in phytotoxicity was noticed particularly for the length of the shoot of Oryza sativa. A significant decrease in genotoxicity after decolourisation was also proven.

\section{Conclusions}

Both tested Klebsiella strains have a significant decolourisation potential for the dyes of different classes (fluorone, azo and triphenylmethane class). The tested bacteria have a great potential to remove $\mathrm{BG}$ and $\mathrm{EB}$ as single substances and mixtures. The dye concentration and type affect the decolourisation effectiveness. The best dye removal results were obtained for Bengal rose, and the worst result was obtained for crystal violet. The strain Bz4 was more sensitive to higher concentrations of crystal violet and brilliant green. The brilliant green decolourisation in the concentration test had higher efficacy than the removal of Evans blue and dye mixture. Between two tested strains, differences in dye removal potential were observed. The best results were obtained for the strain Bz4 in the concentration test and main experiment for the samples with Evans blue and the dye mixture regardless of the process conditions. In the main experiment with brilliant green, the best results were obtained for the strain Rz7, which is similar to the results of the decolourisation potential test. The concentration test shows worse removal results of brilliant green and Evans blue than the potential tests (at identical dye concentrations), which was related to different volumes of medium in the tests, whereas the inoculum volume was identical. 
High adsorption of dyes by the biomass of the strain Bz4 was observed from the beginning of the experiment, whereas for the strain Rz7, this situation was only observed in the samples with the dye mixture. The process conditions significantly affect the rate of decolourisation effectiveness for both tested strains. The best removal of azo Evans blue and the dye mixture was obtained in static and semistatic samples, and the best removal of TPM brilliant green was obtained in the static samples. The zootoxicity decreased in all samples with living biomass of the strain Bz4 but only in the samples with single dyes for the strain Rz7. The phytotoxicity only decreased for the strain Bz4 in the samples with BG and dye mixture and for strain Rz7 only in the samples with BG. The process conditions did not affect the changes in sample toxicity. The high decolourisation potential of both Klebsiella strains is related to the reduction in toxicity class, which suggests the possibility of their application in larger scale.

Acknowledgments This research has been supported by a grant from the Ministry of Science and Higher Education (20072010)_research project number N523 178533.

Open Access This article is distributed under the terms of the Creative Commons Attribution License which permits any use, distribution, and reproduction in any medium, provided the original author(s) and the source are credited.

\section{References}

Alhassani, H. A., Rauf, M. A., \& Ashraf, S. S. (2007). Efficient microbial degradation of Toulidine Blue dye by Brevibacillus sp. Dyes and Pigments, 75, 395-400. doi:10.1016/j.dyepig. 2006.06.019.

An, S. Y., Min, S. K., Cha, I. H., Choi, Y. L., Cho, Y. S., Kim, C. H., \& Lee, Y. C. (2002). Decolorization of triphenylmethane and azo dyes by Citrobacter sp. Biotechnology Letters, 24, 1037-1040.

Azmi, W., Kumar Sani, R., \& Chand Banerjee, U. (1998). Biodegradation of triphenylmethane dyes. Enzyme and Microbial Technology, 22, 185-191.

Banat, I. M., Nigam, P., Singh, D., \& Marchant, R. (1996). Microbial decolorization of textile-dye-containing effluents: a review. Bioresource Technology, 58, 217-227.

Boye, K., \& Hansen, D. S. (2003). Sequencing of 16S rDNA of Klebsiella: taxonomic relations within the genus and to other Enterobacteriaceae. International Journal of Medical Microbiology, 292, 495-503.

Chen, K., Wu, J., Liou, D., \& Hwang, S.-C. (2003). Decolorization of the textile dyes by newly isolated bacterial strains. Journal of Biotechnology, 101, 57-68.

Cui, D., Li, G., Zhao, D., Gu, X., Wang, C., Zhao, M. (2012). Microbial community structures in mixed bacterial consortia for azo dye treatment under aerobic and anaerobic conditions. Journal of Hazardous Materials, 221-222:185-192. doi:10. 1016/j.jhazmat.2012.04.032

Eichlerova, I., Homolka, L., \& Nerud, F. (2006). Synthetic dye decolorization capacity of white rot fungus Dichomitus squalens. Bioresource Technology, 97, 2153-2159.

Elizalde-Gonzales, M. P., Fuentes-Ramirez, L. E., \& GuevaraVilla, M. R. G. (2009). Degradation of immobilized azo dyes by Klebsiella sp. UAP-b5 isolated from maize bioadsorbent. Journal of Hazardous Materials, 161, 769-774. doi:10.1016/ j.jhazmat.2008.04.023.

Forgacs, E., Cserhati, T., \& Oros, G. (2004). Removal of synthetic dyes from wastewaters: a review. Environment International, 30, 953-971. doi:10.1016/j.envint.2004.02.001.

Franciscon, E., Zille, A., Dias Guimaro, F., Ragagnin de Menezes, C., Durrant, L. R., \& Cavaco-Paulo, A. (2009a). Biodegradation of textile azo dyes by facultative Staphylococcus arlettae strain VN-11 using a sequential microaerophilic/aerobic process. International Biodeterioration and Biodegradation, 63, 280-288. doi:10. 1016/j.ibiod.2008.10.003.

Franciscon, E., Zille, A., Fantinatti-Garboggini, F., Serrano Silva, I., Cavaco-Paulo, A., \& Durrant, L. R. (2009b). Microaerophillic-aerobic sequential decolourization/ biodegradation of textile azo dyes by a facultative Klebsiella sp. strain VN-31. Process Biochemistry, 44, 446452. doi:10.1016/j.procbio.2008.12.009.

Hamid, M., \& Rehman, K. (2009). Potential applications of peroxidases. Food Chemistry, 115, 1177-1186. doi:10.1016/j. foodchem.2009.02.035.

Hu, T. L. (2001). Kinetics of azoreductase and assessment of toxicity of metabolic products from azo dyes by Pseudomonas luteola. Water Science and Technology, 43, 261-269.

Isik, M., \& Sponza, D. T. (2003). Effect of oxygen on decolourization of azo dyes by Escherichia coli and Pseudomonas sp. and fate of aromatic amines. Process Biochemistry, 38, 1183-1192.

Jadhav, J. P., Kalyani, A. A., Telke, A. A., Phugare, S. S., \& Govindwar, S. P. (2010). Evaluation of the efficacy of bacterial consortium for the removal of color, reduction of heavy metals, and toxicity from textile dye effluent. Bioresource Technology, 101, 165-173. doi:10.1016/j.biortech.2009.08.027.

Jang, M. S., Lee, Y. M., Kim, C. H., Lee, J. H., Kang, D. W., Kim, S. J., \& Lee, Y. C. (2005). Triphenylmethane reductase from Citrobacter sp. strain KCTC 18061P: purification, characterization, gene cloning, and overexpression of a functional protein in Escherichia coli. Applied and Environmental Microbiology, 71(12), 7955-7960. doi:10.1128/AEM.71.12. 7955-7960.2005.

Jonas, D., Spitzmüller, B., Daschner, F. D., Verhoef, J., \& Brisse, S. (2004). Discrimination of Klebsiella pneumoniae and Klebsiella oxytoca phylogenetic groups and other Klebsiella species by use of amplified fragment length polymorphism. Research in Microbiology, 155, 17-23. doi:10.1016/j.resmic. 2003.09.011.

Kalyani, D. C., Telke, A. A., Dhanve, R. S., \& Jadhav, J. P. (2009). Ecofriendly biodegradation and detoxification of Reactive Red 2 textile dye by newly isolated Pseudomonas sp. SUK1. Journal of Hazardous Materials, 163, 735-742. doi: 10.1016/j.jhazmat.2008.07.020. 
Koyani, R. D., Sanghvi, G. V., Sharma, R. K., \& Rajput, K. S. (2013). Contribution of lignin degrading enzymes in decolourisation and degradation of reactive textile dyes. International Biodeterioration and Biodegradation, 77, 1-9.

Nigam, P., McMullan, G., Banat, I. M., \& Marchant, R. (1996). Decolorization of effluent from the textile industry by a microbial consortium. Biotechnological Letters, 18(1), 117120.

O' Connell, K., Kelly, J., \& NiRiain, U. (2010). A rare case of softtissue infection caused by Raoultella planticola. Case Reports in Medicine. doi:10.1155/2010/134086. Article ID 134086.

Olson, D. S., Jr., Asare, K., Lyons, M., \& Hofinger, D. M. (2013). A novel case of Raoultella planticola urinary tract infection. Infection, 41, 259-261. doi:10.1007/s15010-012-0294-x.

Padamavathy, S., Sandhya, S., Swaminathan, K., Subrahmanyam, Y. V., \& Kaul, S. N. (2003). Comparison of decolorization of reactive azo dyes by microorganisms isolated from various source. Journal of Environmental Sciences, 15, 628-632.

Pearce, C. I., Lloyd, J. R., \& Guthrie, J. T. (2003). The removal of colour from textile wastewater using whole bacterial cells: a review. Dyes and Pigments, 58, 179-196.

Podschun, R., Fischer, A., \& Ullman, U. (2000). Expression of putative virulence factors by clinical isolates of Klebsiella planticola. Journal of Medical Microbiology, 49, 115-119.

Pointing, S. B., \& Vrijmoed, L. L. P. (2000). Decolorization of azo and triphenylmethane dyes by Pycnoporus sanguineus producing laccase as the sole phenoloxidase. World Journal of Microbiology and Biotechnology, 16, 317-318.

Przystaś, W., Zabłocka-Godlewska, E., \& Grabińska-Sota, E. (2009). Screening of dyes decolorizing microorganisms strains. Polish Journal of Environmental Studies, 18(2B), 69-73.

Przystaś, W., Zabłocka-Godlewska, E., \& Grabińska-Sota, E. (2012). Biological removal of azo and triphenylmethane dyes and toxicity of process by-products. Water, Air, and Soil Pollution, 223, 1581-1592. doi:10.1007/s11270-011-0966-7.

Przystaś, W., Zabłocka-Godlewska, E., \& Grabińska-Sota, E. (2013). Effectiveness of dyes removal by mixed fungal cultures and toxicity of their metabolites. Water, Air, and Soil Pollution, 224, 1534. doi:10.1007/s11270-013-1534-0.

Salyers, A.A., Whitt, D.D. (2000). Microbiology: diversity, disease, and the environment. 1st edition. New, York: Wiley.

Sani, R. K., \& Banerjee, U. C. (1999). Decolorization of triphenylmethane dyes and textile and dye-stuff effluent by Kurthia sp. Enzyme and Microbial Technology, 24, 433-437.

Saratale, R. G., Saratale, G. D., Chang, J. S., \& Govindwar, S. P. (2010). Decolorization and biodegradation of reactive dyes and dye wastewater by a developed bacterial consortium. Biodegradation, 21, 999-1015. doi:10.1007/s10532-0109360-1.

Saratale, R. G., Saratale, G. D., Chang, J. S., \& Govindwar, S. P. (2011). Bacterial decolourization and degradation of azo dyes: a review. Journal of Taiwan Institute of Chemical Engineers, 42, 138-157. doi:10.1016/j.jtice.2010.06.006.

Schlegel, H.G. (1993). General microbiology, 7th edition. Cambridge, UK: Cambridge University Press.

Sharma, D. K., Saini, H. S., Singh, M., Chimni, S. S., \& Chandha, B. S. (2004). Isolation and characterization of microorganisms capable of decolorizing various triphenylmethane dyes. Journal of Basic Microbiology, 44(1), 59-65. doi:10.1002/ jobm.200310334.
Somasiri, W., Ruan, W., Xiufen, L., \& Jian, C. (2006). Decolourization of textile wastewater containing acid dyes in UASB reactor system under mixed anaerobic granular sludge. Electronic Journal of Environmental, Agricultural and Food Chemistry, 5(1), 1224-1234.

Srinivasan, A., \& Viraraghavan, T. (2010). Decolorization of dye wastewater by biosorbents: a review. Journal of Environmental Management, 91, 915-1929. doi:10.1016/j. jenvman.2010.05.003.

Stolz, A. (2001). Basic and applied aspects in the microbial degradation of azo dyes. Applied Microbiology and Biotechnology, 56, 69-80. doi:10.1007/s002530100686.

Swamy, J., \& Ramsay, J. A. (1999). The evaluation of white-rot fungi in the decoloration of textile dyes. Enzyme and Microbial Technology, 24, 130-137. doi:10.1016/S01410229(98)00105-7.

Tony, B. D., Goyal, D., \& Khanna, S. (2009). Decolorization of textile azo dyes by aerobic bacterial consortium. International Biodeterioration and Biodegradation, 63, 62469. doi:10.1016/j.ibiod.2009.01.003.

Wang, J., Qiao, M., Wei, K., Ding, J., Liu, Z., Zhang, K., \& Huang, X. (2011). Decolorizing activity of malachite green and its mechanism involved in dye biodegradation by Achromobacter xylosoxidans MG1. Journal of Molecular Microbiology and Biotechnology, 20, 220-227. doi:10. 1159/000330669.

Wang, J., Gao, F., Liu, Z., Qiao, M., Niu, X., et al. (2012). Pathway and molecular mechanisms for malachite green biodegradation in Exiguobacterium sp. MG2. PLoS ONE, 7(12), e51808. doi:10.1371/journal.pone.0051808.

Westbrook, G. L., Mohr O’Hara, C., Roman, S. B., \& Millere, M. (2000). Incidence and identification of Klebsiella planticola in clinical isolates with emphasis on newborns. Journal of Clinical Microbiology, 38(4), 1495-1497.

Wong, P. K., \& Yuen, P. Y. (1998). Decolourization and biodegradation of N, N'-dimethyl-p-phenylenediamine by Klebsiella pneumonia RS-13 and Acetobacter liquefaciens S-1. Journal of Applied Microbiology, 85, 79-87.

Wu, J., Jung, B., Kim, K., Lee, Y., \& Sung, N. (2009). Isolation and characterization of Pseudomonas otitidis WL-13 and its capacity to decolorize triphenylmethane dyes. Journal of Environmental Sciences, 21, 960-964. doi:10.1007/s00253012-4476-3.

Wu, Y., Xiao, X., Xu, C., Cao, D., Du, D. (2012). Decolorization and detoxification of a sulfonated triphenylmethane dye aniline blue by Shewanella oneidensis MR-1 under anaerobic conditions. Applied Microbiology and Biotechnology. doi:10. 1007/s00253-012-4476-3

Van der Zee, F. P., \& Villaverde, S. (2005). Combined anaerobicaerobic treatment of azo dyes - a short review of bioreactor studies. Water Research, 39, 1425-1440.

Vijaykumar, M. H., Vaishampayan, P. A., Shouche, Y. S., \& Karegoudar, T. B. (2007). Decolourization of naphtalenecontaining sulfonated azo dyes by Kerstersia sp. strain VKY1. Enzyme and Microbial Technology, 40, 204-211. doi:10.1016/j.enzmictec.2006.04.001.

Younes, S., Bouallagui, Z., \& Sayadi, S. (2012). Catalytic behavior and detoxifying ability of an atypical homotrimeric laccase from the thermophilic strain Scytalidium thermophilum on selected azo and triarylmethane dyes. Journal of Molecular Catalysis B: Enzymatic, 79, 41-48. 
Zabłocka-Godlewska, E., Przystaś, W., \& Grabińska-Sota, E. (2009). Decolourization of triphenylmethane dyes and ecotoxicity their end products. Environment Protection Engineering, 35(1), 161-169.

Zabłocka-Godlewska, E., Przystaś, W., \& Grabińska-Sota, E. (2012). Decolourization of diazo Evans blue by two strains of Pseudomonas fluorescens isolated from different wastewater treatment plants. Water, Air, and Soil Pollution, 223, 5259-5266. doi:10.1007/s11270-012-1276-4.

Zabłocka-Godlewska, E., Przystaś, W., \& Grabińska-Sota, E. (2014). Decolourisation of different dyes by two Pseudomonas strains under various growth conditions.
Water, Air, and Soil Pollution, 225, 1846. doi:10.1007/ s11270-013-1846-0.

Zhang, M.-M., Chen, W.-M., Chen, B.-Y., Chang, C.-T., Hsueh, C.-C., Ding, Y., Lin, K.-L., \& Xu, H. (2010). Comparative study on characteristic of azo dye decolorization by indigenous decolorizers. Bioresource Technology, 101, 2651-2656. doi:10.1016/j.biortech. 2009.10.070.

Zlotnikov, A. K., Shapovalowa, Y. N., \& Makarov, A. A. (2001). Association of Bacillus firmus E3 and Klebsiella terrigena E6 with increased ability for nitrogen fixation. Soil Biology and Biochemistry, 33, 1525-1530. 